\title{
Oxidative Stress, Nrf2 and Keratin Up-regulation Associate With Mallory-Denk Body Formation in Mouse Erythropoietic Protoporphyria
}

\author{
Amika Singla, ${ }^{1}$ David S. Moons, ${ }^{2}$ Natasha T. Snider, ${ }^{1}$ Elizabeth R. Wagenmaker, ${ }^{1}$ \\ V. Bernadene Jayasundera, ${ }^{1}$ and M. Bishr Omary ${ }^{1,3}$
}

\begin{abstract}
Mallory-Denk bodies (MDBs) are hepatocyte inclusions commonly seen in steatohepatitis. They are induced in mice by feeding 3,5-diethoxycarbonyl-1,4-dihydrocollidine (DDC) for 12 weeks, which also causes porphyrin accumulation. Erythropoietic protoporphyria (EPP) is caused by mutations in ferrochelatase ( $f(h)$, and a fraction of EPP patients develop liver disease that is phenocopied in $\mathrm{Fech}^{\mathrm{m} 1 \mathrm{Pas}}$ mutant (fch/fch) mice, which have an inactivating fch mutation. fch/fch mice develop spontaneous MDBs, but the molecular factors involved in their formation and whether they relate to DDC-induced MDBs are unknown. We tested the hypothesis that fch mutation creates a molecular milieu that mimics experimental drug-induced MDBs. In 13- and 20-week-old fch/fch mice, serum alkaline phosphatase, alanine aminotransferase, and bile acids were increased. The 13 -week-old fch/ fch mice did not develop histologically evident MDBs but manifested biochemical alterations required for MDB formation, including increased transglutaminase- 2 and keratin overexpression, with a greater keratin 8 (K8)-to-keratin 18 (K18) ratio, which are critical for drug-induced MDB formation. In 20-week-old fch/fch mice, spontaneous MDBs were readily detected histologically and biochemically. Short-term (3-week) DDC feeding markedly induced MDB formation in 20-week-old fch/fch mice. Under basal conditions, old fch/fch mice had significant alterations in mitochondrial oxidative-stress markers, including increased protein oxidation, decreased proteasomal activity, reduced adenosine triphosphate content, and Nrf2 (redox sensitive transcription factor) up-regulation. Nrf2 knockdown in HepG2 cells down-regulated K8, but not K18. Conclusion: Fch/fch mice develop age-associated spontaneous MDBs, with a marked propensity for rapid MDB formation upon exposure to DDC, and therefore provide a genetic model for MDB formation. Inclusion formation in the fch/fch mice involves oxidative stress which, together with $\mathrm{Nrf2}$-mediated increase in K8, promotes MDB formation. (HepaTOLOGY 2012;56:322-331)
\end{abstract}

$\mathrm{E}$ rythropoietic protoporphyria (EPP) is an inherited disorder caused by mutations in the ferrochelatase (Fch) gene. ${ }^{1,2}$ More than 40 molecular defects have been described in Fch gene in EPP patients. ${ }^{3}$ Mitochondrial ferrochelatase catalyzes the insertion of ferrous iron into protoporphyrin IX (PPIX), thereby regulating heme biosynthesis. ${ }^{1}$ Reduced ferrochelatase activity in EPP causes excessive accumulation of PP-IX in red blood cells (RBCs), skin, and liver. ${ }^{4}$ The disease is characterized by cutaneous photosensitiv- ity as PP-IX becomes phototoxic upon light exposure. ${ }^{4}$ Approximately $20 \%$ of patients exhibit hepatic manifestations, and 5\%-10\% progress to endstage liver disease. ${ }^{4}$ Genetic background has been suggested as a key determinant in the variable clinical symptoms in $\mathrm{EPP}^{3}$

The $\mathrm{Fech}^{\mathrm{m} 1 \mathrm{Pas}}$ mutant Balb/c mice (fch/fch) were previously reported by others. ${ }^{5}$ These mice harbor a point mutation in the ferrochelatase gene (resulting in 95\% enzymatic activity loss) and suffer from phototoxicity, hemolytic anemia, and severe hepatic dysfunction. ${ }^{5}$

Abbreviations: ALP, alkaline phosphatase; ALT, alanine aminotransferase; BA, bile acids; DDC, 3,5-diethoxycarbonyl-1,4-dihydrocollidine; EPP, erythropoietic protoporphyria; Fch, ferrochelatase; fchlfch, Fech ${ }^{\text {IIPas }}$ mutant mice; GSTM1, glutathione S-transferase M1; HङE, hematoxylin-eosin; HSE, high salt extracts; K18, keratin 18; K8, keratin 8; Keap-1, Kelch-like ECH associating protein 1; Nrf2, nuclear factor E2 derived 2-like 2; PPIX, protoporphyrin IX; RBCs, red blood cells; TG2, transglutaminase-2; Ub, ubiquitin.

From the ${ }^{1}$ Department of Molecular \& Integrative Physiology, ${ }^{2}$ Department of Pathology, ${ }^{3}$ Department of Medicine, University of Michigan Medical School, Ann Arbor, MI.

Received September 8, 2011; accepted January 27, 2012. 
They have elevated levels of serum transaminases, bilirubin, and hyperlipidemia. ${ }^{6}$ Fech $^{\mathrm{m} 1 \mathrm{Pas}}$ mice develop biliary and parenchymal hepatic injury as evidenced by the presence of hepatocyte ballooning, acidophil bodies, necrosis, and Mallory-Denk bodies (MDBs). ${ }^{7}$ MDBs are markers of hepatocellular injury and are seen after feeding mice for 12 or more weeks with the porphyrinogenic compounds griseofulvin or 3,5-diethoxycarbonyl-1,4-dihydrocollidine (DDC). ${ }^{8}$ Interestingly, MDB formation has not been described in EPP patients and the characterization and mechanism of MDB formation in the $\mathrm{fch} / \mathrm{fch}$ mice has not been addressed.

MDBs are cytoplasmic hyaline inclusions that associate with various liver disorders, including alcoholic and nonalcoholic steatohepatitis. ${ }^{8}$ In the context of hepatitis $\mathrm{C}$ virus infection, $\mathrm{MDB}$ presence is associated with poor prognosis. ' Biochemically, MDBs are composed primarily of the intermediate filament proteins keratins 8 and 18 (K8/K18), ubiquitin (Ub), and the ubiquitin-binding protein p62. ${ }^{8}$ The major molecular processes involved in MDB formation include induction of K8/K18 expression with an increase in K8-toK18 ratio, transglutaminase-2 (TG2) induction, resulting in transamidation and keratin crosslinking, and increased p62 levels. ${ }^{8}$ TG2 induction concomitant with an increase in K8-to-K18 ratio leaves excess $\mathrm{K} 8$ that is unbound to its obligate binding partner $\mathrm{K} 18$, which is significant because $\mathrm{K} 8$ appears to be a preferential TG2 substrate (compared with K18) and TG2null mice do not form DDC-induced MDBs. ${ }^{10}$

Oxidative stress strongly associates with DDCinduced MDB formation in $\mathrm{FVB} / \mathrm{N}$ mice (male $>$ female) due to differences in DDC metabolite formation. ${ }^{11}$ Similarly, $\mathrm{C} 3 \mathrm{H}$ mice form far fewer MDBs, as compared with C57BL mice, due to their ability to maintain levels and subcellular distribution of the protective enzymes glyceraldehyde-3-phosphate-dehydrogenase and nucleoside-diphosphate-kinase under oxidative stress. ${ }^{12}$ Additionally, S-adenosyl methionine prevents the formation of MDBs in DDC-primed mice by, in part, normalizing an otherwise compromised proteasomal activity. ${ }^{13}$ Expression-profile analysis of $\mathrm{fch} / \mathrm{fch}$ mouse livers showed major alterations in several oxidative stress-response genes including glutathione-S-transferase, superoxide dismutase, and nuclear factor E2 derived 2-like-2 (Nrf2). ${ }^{6}$ Further, exogenous treatment of $\mathrm{HepG} 2$ cells with protoporphyrin increases intracellular $\mathrm{H}_{2} \mathrm{O}_{2}$, thereby contributing to oxidative stress. ${ }^{14}$

We hypothesized that fch mutation creates a molecular milieu that mimics experimental drug-induced MDBs. Upon testing this hypothesis we delineated the genetic susceptibility of $\mathrm{Fech}^{\mathrm{mlPas}}$ mice to spontaneous and druginduced MDB formation using various biochemical and molecular approaches. Our results support the importance of oxidative stress and $\mathrm{Nrf2}$ in both spontaneous and DDC-induced MDB formation in Fech ${ }^{\text {m1Pas }}$ mice.

\section{Materials and Methods}

Antibodies Used. K8 (Troma-I) (Developmental Studies Hybridoma Bank); glutathione-S-transferaseM-1 (GSTM1), Ub, and Nrf2 (Santa Cruz Biotechnology); mouse/human K8 and K18 (antibody-8592); mouse/human K18 (antibody-4668) ${ }^{11}$; p62 (SigmaAldrich); TG2, $\beta$-tubulin, human K8 (TS1), and human K18 (DC10) (Thermo Scientific).

Animal Experiments. All animal studies were approved by the Animal Use and Care Committee (University of Michigan). Fech ${ }^{\text {m1Pas }}$ mice (Balb/c background; Jackson Laboratories) were screened using a polymerase chain reaction (PCR)-based protocol. The 13- and 20week-old mice were used to study spontaneous MDB formation. MDB induction in 20-week-old mice was done by feeding with LabDiet 5001 (PMI Nutrition International) containing $0.1 \%$ DDC (Sigma-Aldrich) (3 weeks). Age-matched controls were fed a standard mouse diet. FVB mice were also fed $0.1 \%$ DDC ( 2 to 10 days) to examine oxidative stress and proteasome inhibition. Mice were euthanized by $\mathrm{CO}_{2}$ inhalation and intracardiac blood was collected for measurement of alkaline phosphatase (ALP), alanine aminotransaminase (ALT), and bile acids (BA) (using the Vetscan-vs2 instrument; Abaxis). Livers were harvested and apportioned for: hematoxylin-eosin (H\&E) staining, biochemical and molecular analysis, and immunofluorescence staining.

RNA Extraction and Quantitative Real-Time $\boldsymbol{P C R}$. Total RNA was extracted utilizing Qiagen RNeasy kits. TaqMan Reverse Transcriptase kit (Applied

\footnotetext{
Supported by NIH R01 DK52951 and the Department of Veterans Affairs (to M.B.O.); NIH Michigan Gastrointestinal Peptide Research Center P30 DK34933; and NIH F32 DK093202 (to A.S.).

Address reprint requests to: Bishr OmaryUniversity of Michigan Medical School, Department of Molecular \& Integrative Physiology, 7744 Medical Science Building II, 1137 Catherine St., Ann Arbor, MI 48109. fax: 734-936-8813.

Copyright $(2012$ by the American Association for the Study of Liver Diseases.

View this article online at wileyonlinelibrary.com.

DOI 10.1002/hep. 25664

Potential conflict of interest: Nothing to report.

Additional Supporting Information may be found in the online version of this article.
} 
Biosystems) was used to translate RNA into complementary DNA (cDNA), which was subjected to realtime PCR (MyiQ real time PCR detection system, Biorad) and amplified by Brilliant SYBR green master mix utilizing gene specific primers (Supporting Table 1).

Total Lysates, High Salt Extracts (HSE) Preparation, and Immunoblotting. For total lysates, livers were homogenized in sodium dodecyl sulfate (SDS)containing sample buffer. HSE were prepared as described $^{15}$ to obtain keratin-enriched fractions. Equal protein amounts were loaded (4\%-20\% gradient SDSpolyacrylamide gels) and stained by Coomassie blue or transferred to polyvinylidene-difluoride membranes and immunoblotted using relevant antibodies.

Histological and Immunofluorescence Studies. H\&Estained liver sections were assessed for MDBs. For immunofluorescence studies, liver sections were fixed in acetone, air-dried, and stained as described. ${ }^{16}$ MDBs were counted using a $40 \times$ lens and seven fields were examined per liver specimen.

Mitochondria Isolation, Protein Oxidation Assay, and Adenosine Triphosphate (ATP) Content. Liver mitochondria were isolated as described. ${ }^{17}$ Mitochondrial lysates were analyzed for oxidized proteins using an OxyBlot Protein Oxidation Detection Kit (Millipore). DNP signals were quantified using ImageJ software and expressed as relative intensity values (mean \pm standard error of the mean [SEM]). Mitochondrial ATP content was measured using an ATP determination kit (Invitrogen).

Nuclear Extracts and $20 S$ Proteasome Activity. $\mathrm{Nu}-$ clear extracts were prepared using nuclear and cytoplasmic extraction reagent kit (Pierce Biotechnology). Extracts were immunoblotted with anti-Nrf2 antibody. Liver $20 \mathrm{~S}$ proteasomal activity was determined using the $20 \mathrm{~S}$ proteasome assay kit (Cayman Chemical).

Cell Culture and Transfections. HepG2 hepatoblastoma cells were transfected with control or Nrf2 small interfering RNA (siRNA) (Santa Cruz Biotechnology) using Lipofectamine RNAiMax (Invitrogen) (48 hours), then used to prepare RNA extracts and protein lysates.

Statistical Analysis. One-way analysis of variance (ANOVA) with Dunnett's post test or unpaired $t$ test was used for statistical analysis. Differences were considered significant at $P<0.05$.

\section{Results}

Fech ${ }^{\text {m1Pas }}$ Mice Exhibit Spontaneous MDB Formation. The presence of MDBs was previously reported in a mouse model of $\mathrm{EPP}^{7}$ although the underlying mechanisms are unknown. We carried out detailed biochemical, serologic, and histological analyses of the livers of these animals. Initial assessment of 20week-old fch/fch mice and their wildtype (wt/wt) and heterozygous (wt/fch) controls indicated no body weight differences, whereas the percent liver-to-body weight ratio was 1.7 to 1.8 -fold higher in $\mathrm{fch} / \mathrm{fch}$ mice relative to $\mathrm{wt} / \mathrm{wt}$ and $\mathrm{wt} / \mathrm{fch}$ mice (Table S2). Serological analysis of the 20-week-old fch/fch mice revealed increased ALP, ALT, and BA levels (Fig. 1A), in agreement with previously reported hepatobiliary injury in $\mathrm{fch} / \mathrm{fch}$ mice. ${ }^{6,18}$

Given that an essential component of drug-induced MDB formation is an up-regulation of keratins with a K8 $>$ K18 ratio and formation of high molecular weight K8-containing crosslinked species, we examined if the same features occur in the genetic fch model. As shown in Fig. 1B, K8 and K18 messenger RNA (mRNA) levels were increased in $\mathrm{fch} / \mathrm{fch}$ mice with a K8-to-K18 ratio of 1.94. Biochemical analysis of fch/ fch livers revealed increased K8/K18 expression (per $\mathrm{mg}$ of liver tissue) as shown by Coomassie staining of the HSE in Fig. 1C. Immunoblotting showed the presence of K8-ubiquitin high-molecular-weight complexes and increased expression of p62 and TG2 in fch/fch mice (Fig. 1C). These data provide biochemical support for spontaneous MDB formation in 20-week-old $\mathrm{fch} / \mathrm{fch}$ mice. Densitometric analysis showed $\approx 2$-fold increase in K8/K18 protein in $\mathrm{fch} / \mathrm{fch}$ livers (Fig. 1D).

Susceptibility of younger Fech ${ }^{\text {m1Pas }}$ mice (13-weekold) to MDB formation was also examined. Similar to the 20-week-old mice, 13-week-old fch/fch mice showed a 1.8-1.9 higher percent liver/body weight (Table S2), and had elevated levels of ALP, ALT, and BA (Supporting Fig. S1A). The 13-week-old mice showed K8 and K18 mRNA induction, with a K8:K18 ratio of 1.25 (Fig. S1B) that is less than the 1.94 ratio seen in the 20-week-old fch/fch mice (Fig. 1B). K8, K18, and TG2 protein levels were increased in 13 -week-old $\mathrm{fch} / \mathrm{fch}$ mice (Fig. S1C). These mice exhibited K8 dimer formation in the absence of $\mathrm{K} 8$ high molecular weight complexes.

MDB Formation in Fech ${ }^{\text {1Pas }}$ Mice Is AgeDependent and Gender-Independent. The above data suggest that young mice begin to show some of the initiating events of MDB formation (increased keratins/TG2) but have not yet progressed to mature MDBs that can be visualized histologically, because $\mathrm{H} \& \mathrm{E}$ staining revealed the presence of MDBs in 20week (Fig. 2A, panels c,d), but not in 13-week-old, $\mathrm{fch} / \mathrm{fch}$ mice (Fig. S2, panels c,d). This was further confirmed biochemically by the limited formation of high-molecular-weight K8-containing complexes and lack of induction of p62, another key constituent of 
Fig. 1. Serum and biochemical analysis of livers of 20-week-old mice. (A) Serum was collected from 20-week-old wt/wt, wt/fch, and fch/fch mice and used to measure ALT (U/L), $\operatorname{ALP}(\mathrm{U} / \mathrm{L})$, and $\mathrm{BA}(\mu \mathrm{mol} / \mathrm{L})$ levels. $N=3 /$ group and $* P<0.05$ compared with wt/wt. (B) K8 and K18 mRNA levels in indicated genotypes were quantified using real-time PCR. The ratio of $\mathrm{K} 8$ to $\mathrm{K} 18 \mathrm{mRNA}$ in $\mathrm{fch} / \mathrm{fch}$ is 1.94. ${ }^{*} P<0.05$ compared with $w t / w t . ~(C)$ Top panel (a) Coomassie stain for HSEs showing increased K8 and K18 expression in fch/ fch mice and (b) immunoblots for $K 8$, ubiquitin, and p62 of the HSEs (prepared using $100 \mathrm{mg}$ of liver tissue, equal fractions were loaded). (c) Total liver lysates were used to examine TG2 levels ( $\beta$-tubulin as a loading control). Each lane corresponds to a separate liver fraction. (D) Quantification of K8/K18 protein bands (from panel $\mathrm{Ca}$ ) by densitometric scanning using ImageJ software.
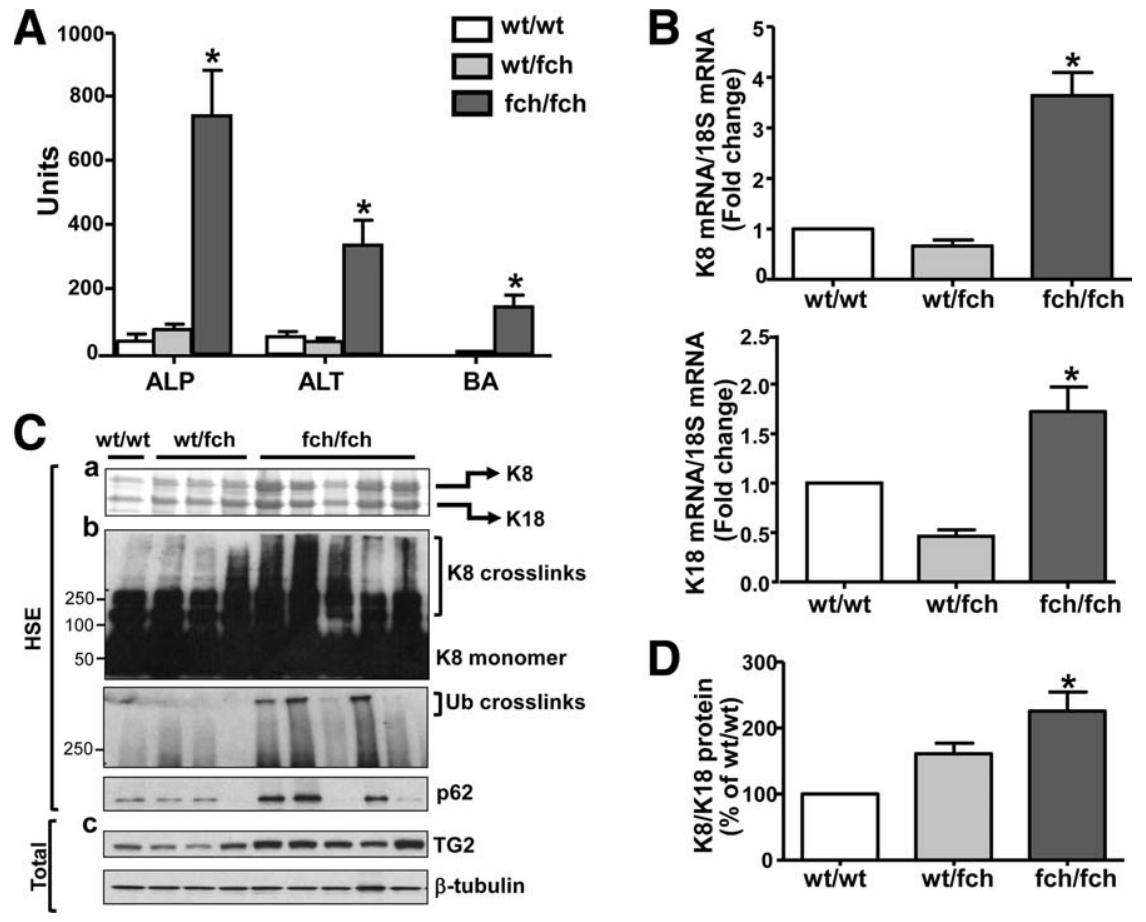

MDBs (Fig. 2B). Immunofluorescence staining revealed prominent keratin and ubiquitin colocalized deposits in 20-week-old (Fig. 3, panels c,d) but not in 13-week-old $\mathrm{fch} / \mathrm{fch}$ livers (Fig. S3), supporting our histological and biochemical findings. Keratin and ubiquitin staining for 20-week-old livers is shown in Fig. S4. Taken together, these data indicate that MDB formation in $\mathrm{Fech}^{\mathrm{m} 1 \mathrm{Pas}}$ mice occurs in an age-dependent manner.

Given that male FVB/N mice are more susceptible to drug-induced MDB formation, ${ }^{11}$ potential gender differences in spontaneous MDB formation were analyzed. Notably, Fech ${ }^{\mathrm{m} 1 \mathrm{Pas}}$ mice (Balb/c background) did not show a gender-based $(\mathrm{M}>\mathrm{F})$ predilection to MDB formation which was confirmed using biochemical (Fig. 2C) and histological (not shown) means.

Fech ${ }^{\text {mIPas }}$ Mice Have Increased Susceptibility to Drug-Induced MDBs. The possibility that the underlying genetic predisposition of spontaneous MDBs renders Fech ${ }^{\mathrm{m} 1 \mathrm{Pas}}$ mice more susceptible to drug-induced MDBs was tested using a modified, 3-week DDC feeding protocol, which is significantly shorter than the standard 12-16 weeks. ${ }^{8}$ Short-term DDC feeding markedly induced K8/K18 mRNA in all three genotypes relative to their non-DDC-fed controls (Fig. 4A). Biochemically, wt/fch mice respond by a dramatic upregulation of $\mathrm{K} 8$ and $\mathrm{K} 18$ (compare Fig. 4B, lanes $2+3$ with 5+6), which parallels increased K8 crosslinking (Fig. 4B). There was a significant increase in MDB numbers in $w t / f c h$ mice $(13.2 \pm 0.4)$ after DDC feeding, whereas MDB numbers was $16.7 \pm 1.9$ in non-
DDC-fed fch/fch mice and $19.2 \pm 2.4$ in DDC-fed $\mathrm{fch} / \mathrm{fch}$ mice. There was also an increase in TG2 levels in DDC-fed mice (Fig. 4B). Histological analysis confirmed the increase in DDC-induced MDBs in $\mathrm{wt} / \mathrm{fch}$ and $\mathrm{fch} / \mathrm{fch}$ mice (Fig. 5). These data indicate that the Fech $^{\text {m1Pas }}$ mice have a markedly enhanced propensity to form drug-induced MDBs.

Mitochondrial Oxidative Stress Is Altered in Fech $^{\text {IPas }}$ Mice. Prior expression-profile analysis of livers from $\mathrm{Fech}^{\mathrm{m} 1 \mathrm{Pas}}$ mice revealed alterations in genes involving heme metabolism, inflammation, and oxidative stress. ${ }^{6}$ Because mitochondria play an important role in reactive oxygen species generation, we examined several mitochondrial oxidative stress markers. fch/fch livers had increased protein oxidized by-products relative to $\mathrm{wt} / \mathrm{wt}$ and $\mathrm{wt} / \mathrm{fch}$ livers (Fig. 6A). Additionally, glutathione-S-transferase-mu-1 (GSTM1, induced during oxidative stress ${ }^{19}$ ) was markedly enhanced under basal conditions in the $\mathrm{fch} / \mathrm{fch}$ livers (Fig. 6B, compare lanes $9+10$ with $1+2$ or $5+6$ ).

Oxidative damage to mitochondria can lead to injury through ATP depletion. Notably, there was a significant decrease in ATP content in fch/fch livers relative to $\mathrm{wt} / \mathrm{wt}$ and $\mathrm{wt} / \mathrm{fch}$ livers, and DDC feeding led to further reduction of ATP, particularly in wt/fch and $\mathrm{fch} / \mathrm{fch}$ livers (Fig. 6C). Given that increased oxidative stress has been shown to decrease proteasomal activity, which is associated with MDB formation, ${ }^{13,20}$ we tested and observed a 2-fold inhibition of the $20 \mathrm{~S}$ proteasomal activity in the $\mathrm{fch} / \mathrm{fch}$ mice and also in 
A

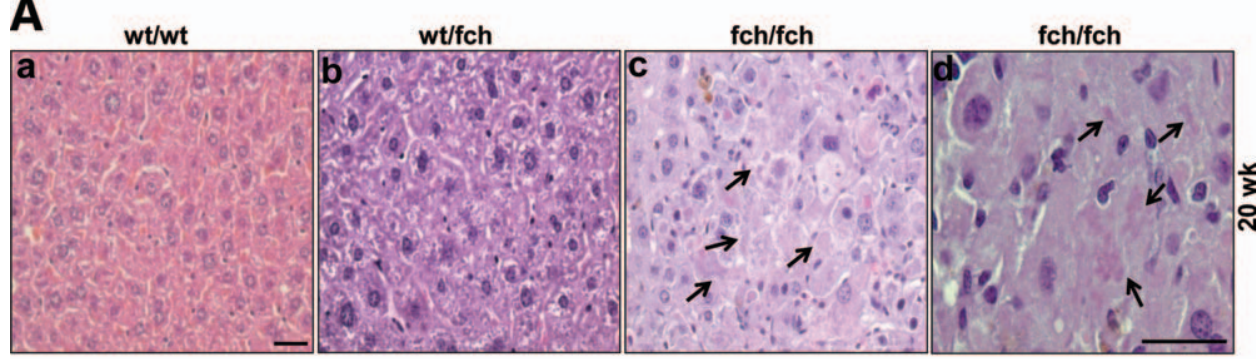

B

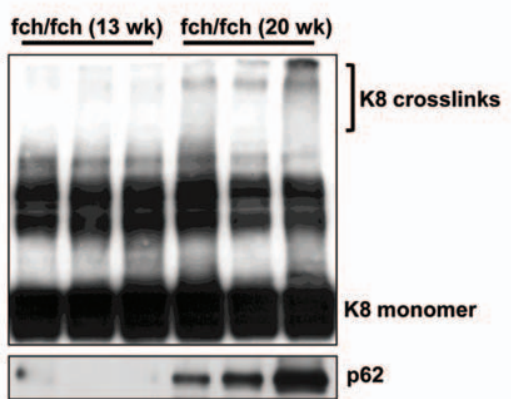

C

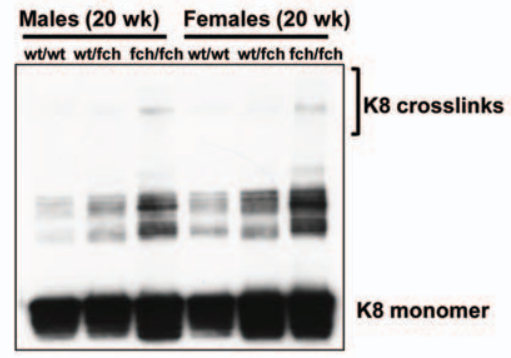

Fig. 2. fch/fch mice exhibit agedependent and gender-independent formation of MDBs. (A) H\&E staining of livers from 20-week-old animals. Panel $c$ represents the image taken using a $40 \times$ objective, whereas panel $d$ is $100 \times$ image of 20-week-old fch/fch livers. Black arrows (panels $\mathrm{c}, \mathrm{d}$ ) highlight the MDBs in the 20-week-old $\mathrm{fch} / \mathrm{fch}$ mice (scale bar $=50 \mu \mathrm{m}$ ). (B) $\mathrm{K} 8$ crosslinking was visualized by immunoblotting HSEs from 13- and 20-week-old fch/fch mice. (C) HSEs from 20-week-old male and female mice were immunoblotted for K8. For panel B, each lane corresponds to separate liver fractions.

the DDC fed wt/wt, wt/fch, and fch/fch mice (Fig. liver. ${ }^{21} \mathrm{Nrf} 2$ regulates multiple antioxidant pathways ${ }^{21}$ 6D). These results suggest that oxidative stress in fch/ fch mice decreases proteasomal activity.

Fech $^{\text {IIPas }}$ Mice Show Increased Expression of Nrf2. Nuclear factor E2 derived 2-like-2 (Nrf2) is a redox sensitive transcription factor expressed in the

and its mRNA is up-regulated in Fech ${ }^{\text {m1Pas }}$ mice based on unvalidated microarray studies. ${ }^{6}$ Therefore, mRNA levels and nuclear protein expression of $\mathrm{Nrf} 2$ in control and DDC-fed wt/wt, wt/fch, and fch/fch livers were analyzed. There was increased Nrf2 liver mRNA
Fig. 3. Analysis of MDB formation using immunofluorescence staining. Liver sections from 20-week-old mice of the indicated genotypes were double stained using K8/K18 (red) and Ub (green) antibodies. Nuclei are shown in blue. MDBs (yellow dots due to colocalization of two epitopes) were noted using $40 \times$ lens in the $\mathrm{fch} / \mathrm{fch}$ livers and are highlighted by white arrows (panel $c$ ). Panel $d$ represents the higher magnification of the boxed area in panel c. Scale bar $=20 \mu \mathrm{m}$.
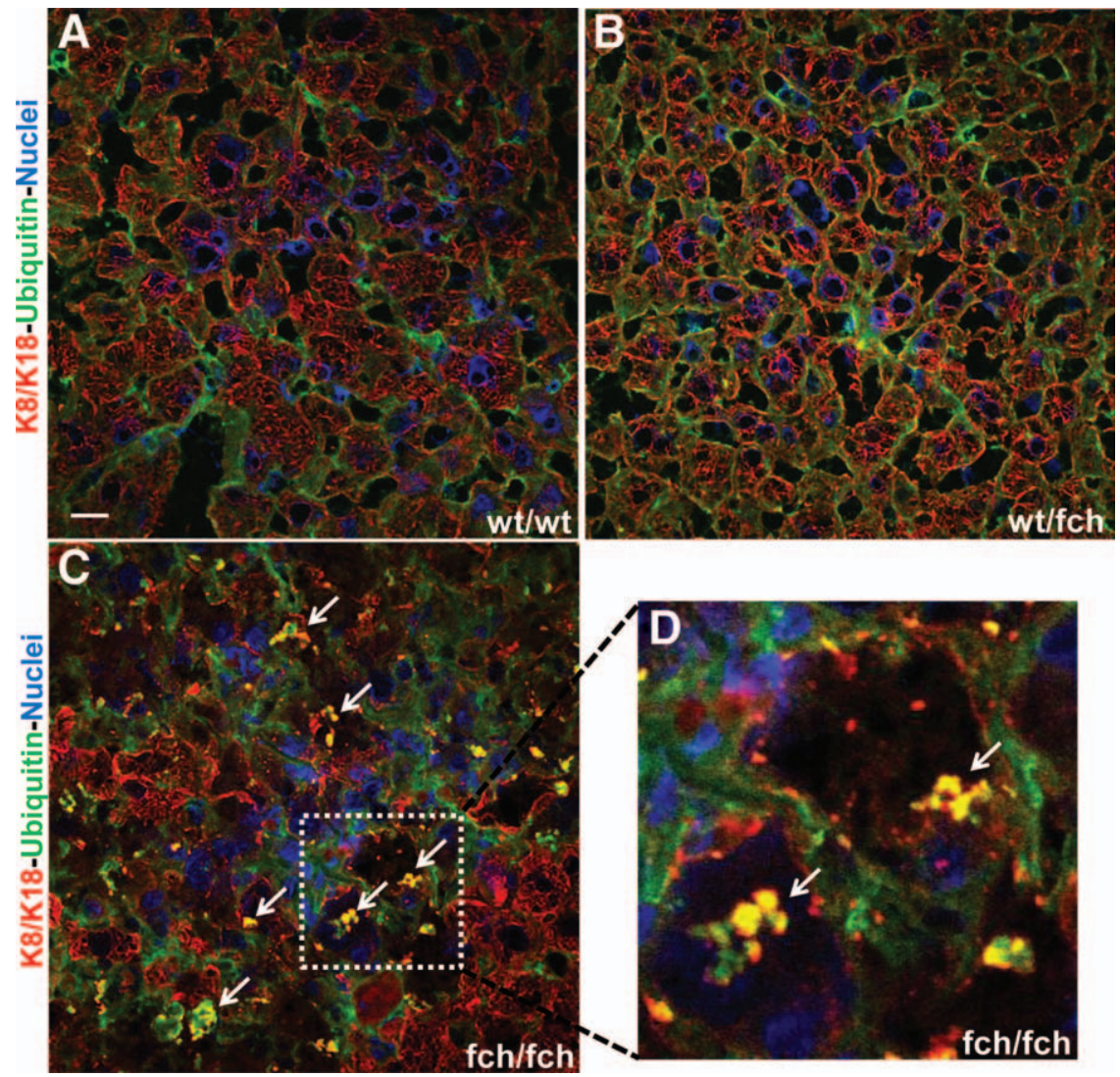
A

Fig. 4. Short-term DDC feeding of $\mathrm{fch} / \mathrm{fch}$ mice induces prominent MDB formation. The 20-week-old wt/wt, wt/fch, and fch/fch mice were fed DDC for 3 weeks. (A) RNA (extracted from the control and DDC livers) was subjected to real-time PCR to examine $\mathrm{K} 8$ and K18 mRNA levels. $\mathrm{N}=3,{ }^{*} P<0.05$ versus wt/wt. (B) HSEs from the control and DDC livers were (a) stained by Coomassie blue or (b) immunoblotted using antibodies to $\mathrm{K} 8$ or TG2. Each lane corresponds to a separate liver fraction.

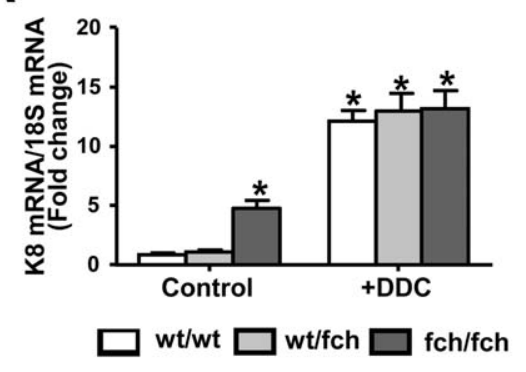

B

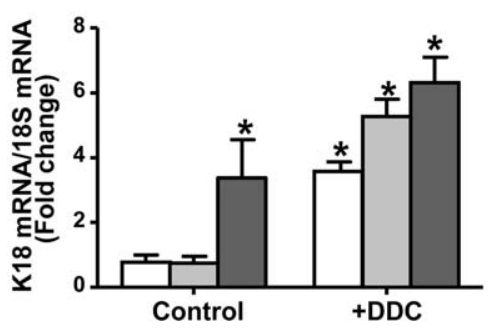

expression $(\approx 3$ fold $)$ in $\mathrm{fch} / \mathrm{fch}$ relative to $\mathrm{wt} / \mathrm{wt}$ mice (Fig. 7A). Short-term DDC feeding induced liver Nrf2 mRNA levels in all mice. Consistent with the mRNA findings, control and DDC-fed $\mathrm{fch} / \mathrm{fch}$ mice had significant induction in nuclear Nrf2 protein (Fig. 7B). These results indicate Nrf2 up-regulation in control and DDC-fed fch/fch mice, likely in response to oxidative stress. To further examine the sequence of events, FVB mice were fed DDC for 2-10 days. Analysis of the DDC-fed livers showed an increase in Nrf2 mRNA and protein expression after 5 days of DDC feeding (Fig. S5A,B). However, there was no inhibition in proteasome activity in 2-day and 5-day DDC-fed livers (Fig. S5C), suggesting that there is another mechanism involved in increasing $\mathrm{Nrf} 2$ expression.
Further, we examined the mitochondrial oxidized proteins, and Oxyblot analysis (Fig. S5D) showed an increase in oxidized protein by-products in 5-day DDC-fed mice, suggesting that oxidative stress is upstream of proteasome inhibition. Nrf2 protein levels were greatly stabilized in M132-treated HepG2 cells, suggesting that proteasome inhibition also help stabilize Nrf2 protein (Fig. S5E).

Nrf2 Regulates K8 but Not K18 Expression. Nrf2 was shown previously to regulate keratin-16 (K16) gene expression in human keratinocytes. ${ }^{22}$ Therefore, we examined the effect of $\mathrm{Nrf} 2$ on $\mathrm{K} 8$ and $\mathrm{K} 18$ expression in HepG2 cells using siRNA knockdown. Nrf2 siRNA but not control siRNA significantly inhibited $\mathrm{K} 8$ but not $\mathrm{K} 18$ mRNA and protein

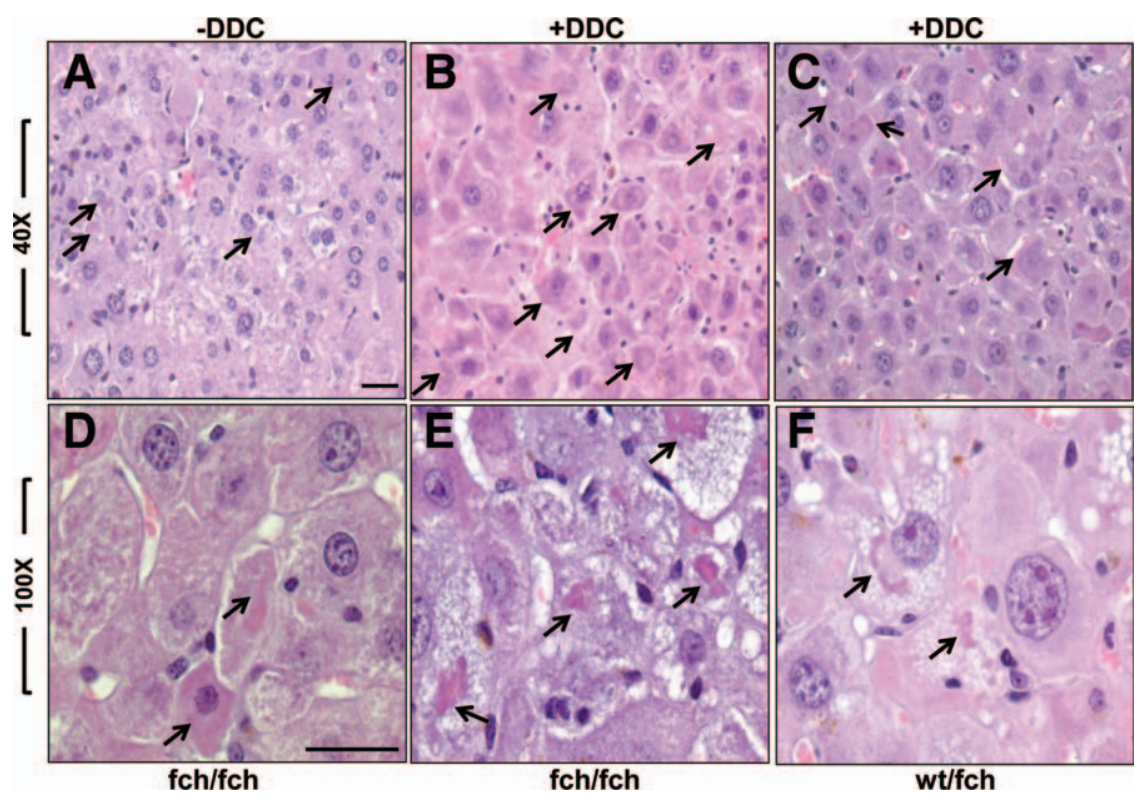

Fig. 5. H\&E staining of liver sections from control and DDC-fed fch/fch and wt/fch mice. H\&E staining was performed to examine the MDBs in livers of DDC-fed mice. MDBs are marked using black arrows (scale bar $=50$ $\mu \mathrm{m})$. Panels a-c are $40 \times$ images and $d-f$ are the $100 \times$ images. 
A wt/wt wt/fch fch/fch
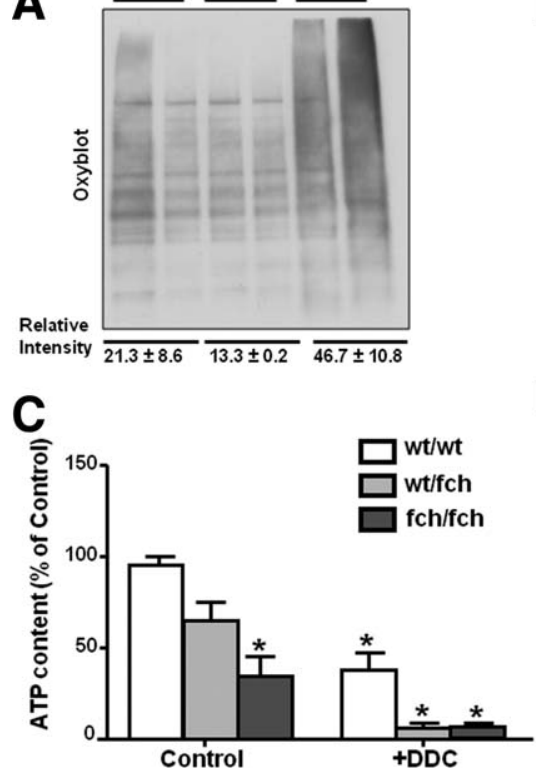

B

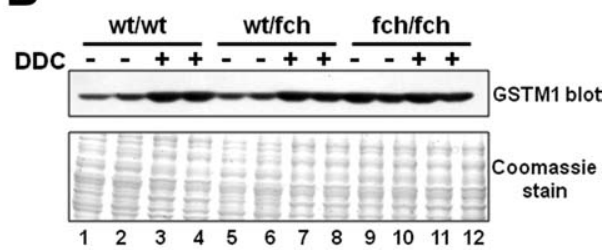

D

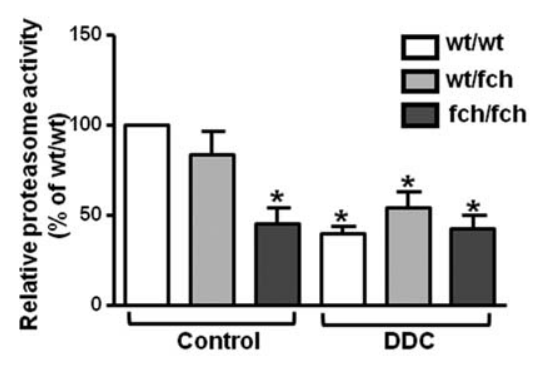

Fig. 6. Comparison of oxidative stress markers in livers of 20-week-old fch/fch versus controls. (A) Protein oxidation was measured as described in Materials and Methods. (B) Lysates of livers from the indicated genotypes (DDC-fed or normal chow) were blotted with GSTM1 antibody. For panels A and B, each of the lanes corresponds to liver preparations from independent mice. (C) Mitochondrial ATP content was measured in the livers isolated from control and DDC-fed mice. (D) $20 S$ proteasomal activity was measured in liver homogenates from control and DDCtreated mice. $\mathrm{N}=3,{ }^{*} P<0.05$ compared versus $\mathrm{wt} / \mathrm{wt}$. expression (Fig. 7C,D). These findings suggest that the $\mathrm{K} 8$ gene is a target for Nrf2.

\section{Discussion}

Relevance of MDBs to EPP in Humans and Mouse Models of EPP. Porphyrias are inherited metabolic disorders that occur due to defects in the heme biosynthetic pathway, and are divided into acute and nonacute porphyrias. ${ }^{23} \mathrm{EPP}$ is a nonacute porphyria caused by mutation in the Fch gene. Two mouse mod- els of EPP have been described to date. The first model was generated by an Fch exon deletion which led to embryo-lethality of the homozygous mice, whereas heterozygous mice developed mild protoporphyria without liver disease. ${ }^{24}$ The second model $\left(\mathrm{Fech}^{\mathrm{m} 1 \mathrm{Pas}}\right)$ was generated by inducing a point mutation in the Fch gene, ${ }^{5}$ which has been a valuable animal model for EPP because it mimics the most severe hepatic forms of the human disease.

The presence of MDBs has been described in the Fech $^{\text {m1Pas }}$ mouse strain and also in the griseofulvin-induced
Fig. 7. $\mathrm{K} 8$ is a target gene for Nrf2. (A) RNA was isolated from the livers of control and DDC-fed mice and quantified for Nrf2 mRNA. (B) Immunoblot analysis (using anti-Nrf2 antibody) of nuclear extracts from control and DDC-fed livers (Coomassie stain is included as a loading control). Representative blot of three independent experiments is shown, and quantification was done from the three experiments ( ${ }^{*} P<0.05$ versus wt/wt). (C) HepG2 cells were transfected with control and Nrf2 siRNA. Real-time PCR was utilized to examine $\mathrm{K} 8$ and K18 mRNA levels. (D) Total lysates were immunoblotted using $\mathrm{K} 8, \mathrm{~K} 18$, and Nrf2 antibodies. $\beta$-Actin served as a loading control. For all the experiments. $\mathrm{N}=3, * P<$ 0.05 .
A

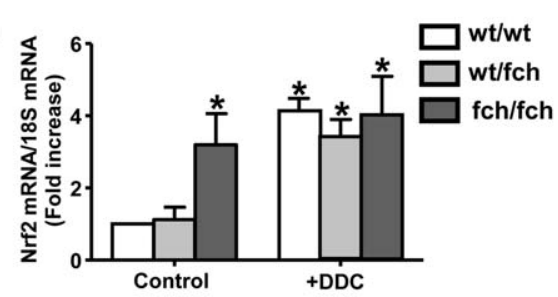

B
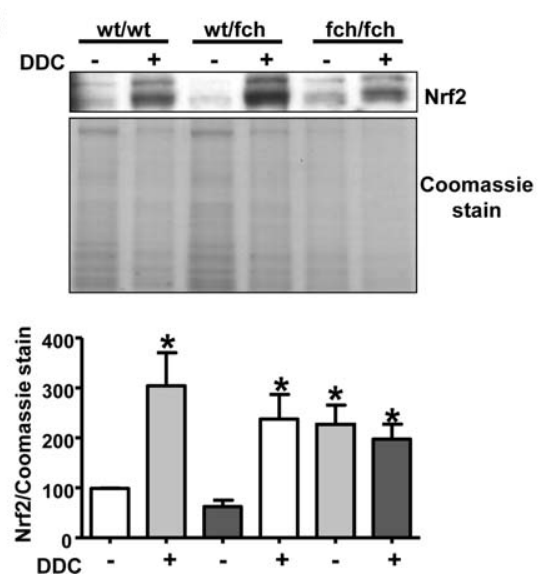

C
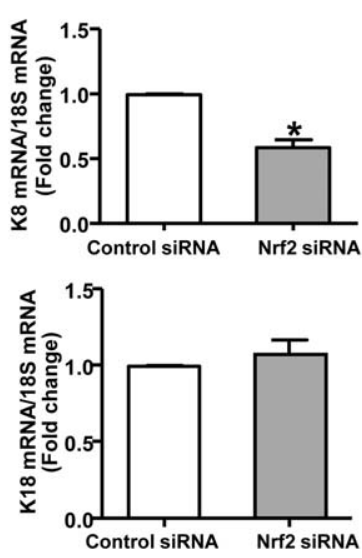

D

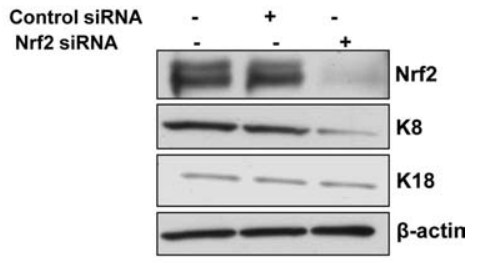


mouse model of EPP. ${ }^{7,25}$ However, MDBs have not been reported in EPP patients. It should be noted that MDBs are visualized in clinical contexts using histological approaches (e.g., H\&E staining), which lack sensitivity for detecting small and early MDBs. ${ }^{16}$ It is possible that some patients with EPP may form MDBs if sensitive methods are employed for their detection, and if indeed found then the genetic background of an individual may be a contributing factor. For example, Hispanics appear to be more predisposed to MDB formation, ${ }^{9,26}$ and clear differences in MDB susceptibility are also noted in different mouse strains. ${ }^{12,16}$ Other potential factors that may contribute to the apparent absence of MDBs in EPP patients (versus the animal models) may be related to differences in porphyrin metabolites across species. In this context, the contribution of porphyria per se to MDB formation is unclear. Certainly, porphyrin accumulation leads to oxidative stress, ${ }^{14}$ although other factors are likely important. The range of accumulation of protoporphyrin-IX (PP-IX) in DDC-fed male $(\approx 550$ $\mathrm{nmol} / \mathrm{g}$ protein $)$ and female $(\approx 1,900 \mathrm{nmol} / \mathrm{g}$ protein $)$ mice $^{11}$ is similar to the porphyria in the $\mathrm{fch} / \mathrm{fch}$ mice $\left(1,000-5,000 \mathrm{nmol} / \mathrm{g}\right.$ protein $\left.^{6,27}\right)$. By comparison, patients with EPP have PP-IX levels in the range of 3,000-8,000 nmol/g tissue, ${ }^{1}$ although the genetic modifiers that result in severe human liver disease in the 5\%$10 \%$ of affected EPP patients are not known.

fchlfch Mice Manifest Spontaneous MDB Accumulation and Enhanced Susceptibility to DrugInduced MDB Formation. Our findings herein characterize the formation of spontaneous and DDC-induced MDBs in $\mathrm{fch} / \mathrm{fch}$ mice and showed that MDBs formation in these mice is age-dependent but gender-independent. The lack of gender-dependency in this model, in contrast to the $\mathrm{FVB} / \mathrm{N}$ drug-induced model, may be due to genetic mouse strain differences (Balb/c versus $\mathrm{FVB} / \mathrm{N}$ ) or may be related to the increased porphyria that might overcome genetic gender-related influences.

The enhanced susceptibility to drug-induced MDB formation, even in the heterozygous $\mathrm{wt} / \mathrm{fch}$ mice, renders these mice very useful for studying MDBs given that MDBs can be induced in these mice within 3 weeks as compared with the standard 12 to 16 -week DDC regimen. Hence, these mice are even more susceptible to MDB formation when compared with another genetic model, which is mice that overexpress K8 (which develop MDBs within 6 weeks of DDC exposure). ${ }^{28}$ The spontaneous formation of MDBs in $\mathrm{fch} / \mathrm{fch}$ mice is also reminiscent of their formation in the K8-overexpressor mice and in the K18-null mice upon aging (both have a $\mathrm{K} 8>\mathrm{K} 18$ ratio). ${ }^{28,29}$

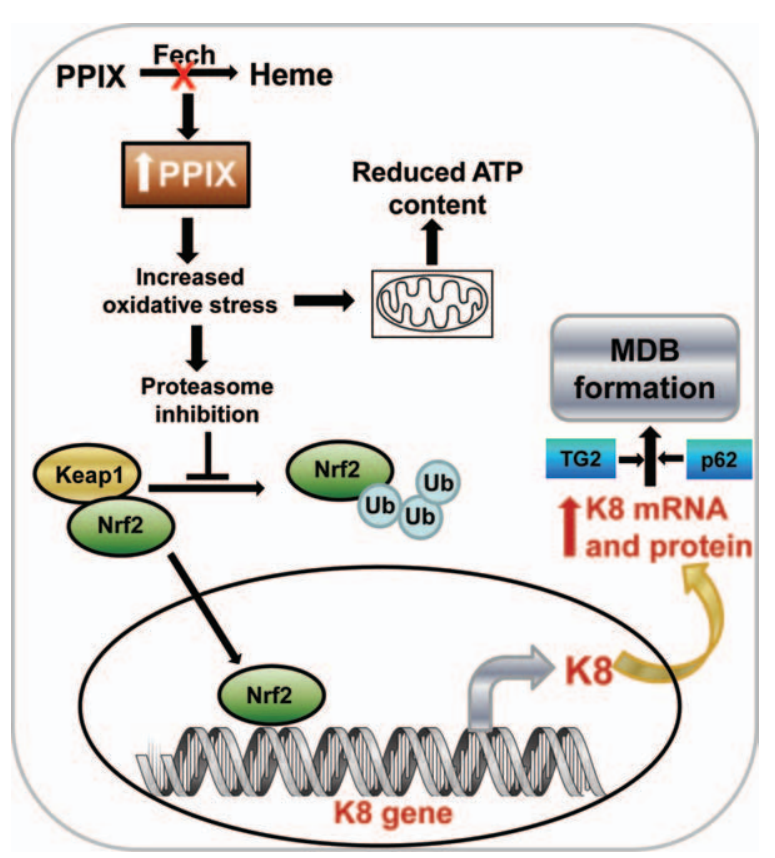

Fig. 8. Schematic of the crosstalk between oxidative stress and MDB formation in the context of Fech mutation. A defect in ferrochelatase leads to accumulation of protoporphyrin-IX (PP-IX) in liver mitochondria, which results in increased mitochondrial oxidative stress and reduced ATP content. The increase in oxidative stress leads to proteasome inhibition, decreased Nrf2 degradation, with subsequent nuclear translocation of Nrf2. Nuclear Nrf2 then binds to the antioxidant response element (ARE) of the $\mathrm{K} 8$ gene and increases $\mathrm{K} 8 \mathrm{mRNA}$, among additional transcriptional regulatory events. The increase in $\mathrm{K} 8$, TG2, and p62 promotes MDB formation. [Color figure can be viewed in the online issue, which is available at wileyonlinelibrary.com.]

Oxidative Stress, Proteasome Function, and Nrf2 in MDB Formation in fchlfch Mice. Oxidative stress plays a major role in several protein aggregation disorders. $^{30,31}$ It is also involved in MDB formation in FVB/ $\mathrm{N}$ and K8-overexpressing mice in response to DDC feeding. ${ }^{11}$ Our findings demonstrate a role for oxidative stress in MDB formation in $\mathrm{fch} / \mathrm{fch}$ mice, and support previously reported alterations in oxidative stress genes in fch/ fch mice and in EPP patients utilizing microarray analysis. ${ }^{3,6}$ In addition, griseofulvin-induced EPP in mice results in ultrastructural changes in liver mitochondria, accumulation of large amounts of protoporphyrin, and low-energy coupling in mitochondria, which suggest blunting of mitochondrial function. ${ }^{32}$ Moreover, treatment of HepG2 cells with protoporphyrin in the absence of light increases intracellular $\mathrm{H}_{2} \mathrm{O}_{2}$ levels, which supports the role of protoporphyrin in causing oxidative stress. ${ }^{14}$ Our data are consistent with the presence of mitochondrial oxidative stress in the $\mathrm{fch} / \mathrm{fch}$ livers, as demonstrated by decreased mitochondrial ATP and increased liver oxidized proteins (Fig. 6; Fig. S5), possibly due to accumulation of protoporphyrin deposits. 
The time course of DDC feeding to FVB animals demonstrated that oxidative stress is upstream of proteasome inhibition and correlates with the increase Nrf2 expression, which becomes further magnified upon proteasome inhibition. Therefore, the observed $50 \%$ decrease in proteasome function in $\mathrm{fch} / \mathrm{fch}$ mice under basal conditions are likely intimately linked to the increased oxidative milieu in the livers of these animals. Reduction in mitochondrial ATP content impairs proteasomal activity, which in turn leads to mitochondrial dysfunction in various disease states. ${ }^{20}$ Furthermore, proteasome inhibition in vivo accelerates MDB formation from 6 weeks to 2 weeks in K8-overexpressing mice, ${ }^{33}$ and a decrease in proteasome activity became normalized upon $S$-adenosylmethionine administration to DDC-fed mice in a short-term rechallenge model. ${ }^{13}$

$\mathrm{Nrf} 2$ is a redox-sensitive transcription factor that protects cells from oxidative stress. ${ }^{21}$ It is sequestered in the cytoplasm by Keap-1 (Kelch-like ECH associating protein 1) under nonstress conditions and is targeted for ubiquitination and proteasomal degradation. ${ }^{21}$ During stress, Nrf2 escapes Keap-1-mediated repression and translocates to the nucleus to up-regulate various genes such as glutathione-S-transferases and heme oxygenase1. ${ }^{21}$ Notably, the phytochemical sulforaphane, which activates $\mathrm{Nrf2}$, up-regulates epidermal keratins K16 and $\mathrm{K}_{1} 7^{34}$ and Nrf2 up-regulates K16 in human keratinocytes. ${ }^{22}$ Furthermore, autophagy deficiency and up-regulation of p62 are known to stabilize $\mathrm{Nrf} 2$, resulting in activation of Nrf2 target genes. ${ }^{35}$ Our findings showed a decrease of K8, but not K18, mRNA and protein upon Nrf2 knockdown in HepG2 cells, and also showed Nrf2 nuclear accumulation in $\mathrm{fch} / \mathrm{fch}$ mice under basal conditions and in $\mathrm{fch} / \mathrm{fch}$, wt/fch, and wt/wt livers after exposure to DDC (Fig. 7). Furthermore, sequence analysis of the 5'-proximal promoter region of K8 and K18 revealed the presence of $\mathrm{Nrf2}$ consensus binding sequence (not shown). This was consistent with the study showing the Nrf2 binding sites on K16 promoter region. ${ }^{22}$ Based on the findings herein, and the established importance of $\mathrm{K} 8$ in MDB formation ${ }^{8}$ and of PPIX in oxidative stress, ${ }^{14}$ we propose a model (Fig. 8) whereby accumulation of PPIX leads to increased mitochondrial oxidative stress that inhibits the Keap-1-mediated Nrf2 degradation, thereby resulting in translocation of $\mathrm{Nrf} 2$ to nucleus and up-regulation of $\mathrm{K} 8$ and other target genes.

\section{References}

1. Bloomer J, Wang Y, Singhal A, Risheg H. Molecular studies of liver disease in erythropoietic protoporphyria. J Clin Gastroenterol 2005;39: S167-S175.
2. McGuire BM, Bonkovsky HL, Carithers RL Jr, Chung RT, Goldstein LI, Lake JR, et al. Liver transplantation for erythropoietic protoporphyria liver disease. Liver Transpl 2005;11:1590-1596.

3. Rufenacht UB, Gouya L, Schneider-Yin X, Puy H, Schafer BW, Aquaron $\mathrm{R}$, et al. Systematic analysis of molecular defects in the ferrochelatase gene from patients with erythropoietic protoporphyria. Am J Hum Genet 1998;62:1341-1352.

4. Casanova-Gonzalez MJ, Trapero-Marugan M, Jones EA, Moreno-Otero R. Liver disease and erythropoietic protoporphyria: a concise review. World J Gastroenterol 2010;16:4526-4531.

5. Tutois S, Montagutelli X, Da Silva V, Jouault H, Rouyer-Fessard P, Leroy-Viard K, et al. Erythropoietic protoporphyria in the house mouse. A recessive inherited ferrochelatase deficiency with anemia, photosensitivity, and liver disease. J Clin Invest 1991;88:1730-1736.

6. Davies R, Schuurman A, Barker CR, Clothier B, Chernova T, Higginson FM, et al. Hepatic gene expression in protoporphyic Fech mice is associated with cholestatic injury but not a marked depletion of the heme regulatory pool. Am J Pathol 2005;166:1041-1053.

7. Libbrecht L, Meerman L, Kuipers F, Roskams T, Desmet V, Jansen P. Liver pathology and hepatocarcinogenesis in a long-term mouse model of erythropoietic protoporphyria. J Pathol 2003;199:191-200.

8. Zatloukal K, French SW, Stumptner C, Strnad P, Harada M, Toivola DM, et al. From Mallory to Mallory-Denk bodies: what, how and why? Exp Cell Res 2007;313:2033-2049.

9. Rakoski MO, Brown MB, Fontana RJ, Bonkovsky HL, Brunt EM, Goodman ZD, et al. Mallory-Denk bodies are associated with outcomes and histologic features in patients with chronic hepatitis C. Clin Gastroenterol Hepatol 2011;9:902-909.

10. Strnad P, Harada M, Siegel M, Terkeltaub RA, Graham RM, Khosla C, et al. Transglutaminase 2 regulates mallory body inclusion formation and injury-associated liver enlargement. Gastroenterology 2007;132:1515-1526.

11. Hanada S, Snider NT, Brunt EM, Hollenberg PF, Omary MB. Gender dimorphic formation of mouse Mallory-Denk bodies and the role of xenobiotic metabolism and oxidative stress. Gastroenterology 2010;138: 1607-1617.

12. Snider NT, Weerasinghe SV, Singla A, Leonard JM, Hanada S, Andrews PC, et al. Energy determinants GAPDH and NDPK act as genetic modifiers for hepatocyte inclusion formation. J Cell Biol 2011;195:217-229.

13. Bardag-Gorce F, Oliva J, Li J, French BA, French SW. SAMe prevents the induction of the immunoproteasome and preserves the 26S proteasome in the DDC-induced MDB mouse model. Exp Mol Pathol 2010; 88:353-362.

14. Koningsberger JC, Rademakers LH, van Hattum J, de la Faille HB, Wiegman LJ, Italiaander E, et al. Exogenous protoporphyrin inhibits Hep G2 cell proliferation, increases the intracellular hydrogen peroxide concentration and causes ultrastructural alterations. J Hepatol 1995;22:57-65.

15. Ku NO, Toivola DM, Zhou Q, Tao GZ, Zhong B, Omary MB. Studying simple epithelial keratins in cells and tissues. Methods Cell Biol 2004;78:489-517.

16. Hanada S, Strnad P, Brunt EM, Omary MB. The genetic background modulates susceptibility to mouse liver Mallory-Denk body formation and liver injury. Hepatology 2008;48:943-952.

17. Tao GZ, Looi KS, Toivola DM, Strnad P, Zhou Q, Liao J, et al. Keratins modulate the shape and function of hepatocyte mitochondria: a mechanism for protection from apoptosis. J Cell Sci 2009;122:3851-3855.

18. Lyoumi S, Abitbol M, Rainteau D, Karim Z, Bernex F, Oustric V, et al. Protoporphyrin retention in hepatocytes and kupffer cells prevents sclerosing cholangitis in erythropoietic protoporphyria mouse model. Gastroenterology 2011;141:1509-1519.

19. Whalen R, Boyer TD. Human glutathione S-transferases. Semin Liver Dis $1998 ; 18: 345-358$.

20. Abou-Sleiman PM, Muqit MM, Wood NW. Expanding insights of mitochondrial dysfunction in Parkinson's disease. Nat Rev Neurosci 2006; 7:207-219.

21. Klaassen CD, Reisman SA. Nrf2 the rescue: effects of the antioxidative/electrophilic response on the liver. Toxicol Appl Pharmacol 2010; 244:57-65. 
22. Endo H, Sugioka Y, Nakagi Y, Saijo Y, Yoshida T. A novel role of the NRF2 transcription factor in the regulation of arsenite-mediated keratin 16 gene expression in human keratinocytes. Environ Health Perspect 2008;116:873-879.

23. Puy H, Gouya L, Deybach JC. Porphyrias. Lancet 2010;375:924-937.

24. Magness ST, Maeda N, Brenner DA. An exon 10 deletion in the mouse ferrochelatase gene has a dominant-negative effect and causes mild protoporphyria. Blood 2002;100:1470-1477.

25. Matilla A, Molland EA. A light and electron microscopic study of the liver in case of erythrohepatic protoporphyria and in griseofulvininduced porphyria in mice. J Clin Pathol 1974;27:698-709.

26. Mohanty SR, Troy TN, Huo D, O'Brien BL, Jensen DM, Hart J. Influence of ethnicity on histological differences in non-alcoholic fatty liver disease. J Hepatol 2009;50:797-804.

27. Fontanellas A, Mazurier F, Landry M, Taine L, Morel C, Larou M, et al. Reversion of hepatobiliary alterations By bone marrow transplantation in a murine model of erythropoietic protoporphyria. HEPATOLOGY 2000;32:73-81.

28. Nakamichi I, Toivola DM, Strnad P, Michie SA, Oshima RG, Baribault $\mathrm{H}$, et al. Keratin 8 overexpression promotes mouse Mallory body formation. J Cell Biol 2005;171:931-937.
29. Magin TM, Schroder R, Leitgeb S, Wanninger F, Zatloukal K, Grund C, et al. Lessons from keratin 18 knockout mice: formation of novel keratin filaments, secondary loss of keratin 7 and accumulation of liverspecific keratin 8-positive aggregates. J Cell Biol 1998;140:1441-1451.

30. Andersen JK. Oxidative stress in neurodegeneration: cause or consequence? Nat Med 2004;10(Suppl):S18-S25.

31. Askanas V, Engel WK. Inclusion-body myositis: a myodegenerative conformational disorder associated with Abeta, protein misfolding, and proteasome inhibition. Neurology 2006;66:S39-48.

32. Tangeras A. Effect of decreased ferrochelatase activity on iron and porphyrin content in mitochondria of mice with porphyria induced by griseofulvin. Biochim Biophys Acta 1986;882:77-84.

33. Harada M, Hanada S, Toivola DM, Ghori N, Omary MB. Autophagy activation by rapamycin eliminates mouse Mallory-Denk bodies and blocks their proteasome inhibitor-mediated formation. HePATOLOGY 2008;47:2026-2035.

34. Kerns M, Depianto D, Yamamoto M, Coulombe PA. Differential modulation of keratin expression by sulforaphane occurs via Nrf2-dependent and -independent pathways in skin epithelia. Mol Biol Cell 2010.

35. Inami Y, Waguri S, Sakamoto A, Kouno T, Nakada K, Hino O, et al. Persistent activation of Nrf2 through p62 in hepatocellular carcinoma cells. J Cell Biol 2011;193:275-284. 